\title{
AUTHOR INDEX OF VOLUME 21
}

Adede, A.O.

Bauernfeind, Stefan

Casey-Lefkowitz, Susan

Ercmann, Sevine

Handler, Tom

Kamto, Maurice

Keltie, Andrew

Koskova, Mahulena

McCaffrey, Stephen C.

Miller, David

Minujín, Facundo Gómez
224 Oberthür, Sebastian 193

150 Pinochet de la Barra, Oscar 205

16 Rest, Alfred 135

68 Robinson, Nicholas A. 216

26 Rublack, Susanne 23

236 Similä, Jukka 72

26 Sheate, W.R. 156

14 Smets, Henri 141

6 Strenger, Hermann J. 55

199 Weiss, Heinrich 153 